\title{
Systematic Review and Subgroup Meta-analysis of Randomized Trials to Determine Tocilizumab's Place in COVID-19 Pneumonia
}

Timothée Klopfenstein (1) · Vincent Gendrin • Aurélie Gerazime · Thierry Conrozier • Jean-Charles Balblanc • Pierre-Yves Royer $\cdot$ Anne Lohse $\cdot$ Chaouki Mezher $\cdot$ Lynda Toko $\cdot$ Cerise Guillochon · Julio Badie $\cdot$ Alix Pierron · N.'dri Juliette Kadiane-Oussou - Marc Puyraveau - Souheil Zayet - For the HNF Hospital tocilizumab multidisciplinary team

Received: May 14, 2021 / Accepted: June 16, 2021 / Published online: July 11, 2021

(C) The Author(s) 2021

\section{ABSTRACT}

Introduction: Tocilizumab randomized clinical trial results are heterogeneous because of the heterogenous population included in them.

Methods: We conducted a meta-analysis with subgroup meta-analysis (PRISMA guidelines) between severe and non-severe COVID-19.

Results: We included nine trials. Overall, the mortality rate was $24.5 \%(821 / 3357)$ in the tocilizumab group and $29.1 \%(908 / 3125)$ in the control group at day 28-30 (pooled OR, 0.85; 95\% CI $0.76-0.96 ; p=0.006$ ). Considering the subgroup analysis, this benefit on mortality was confirmed and amplified in the severe COVID-

T. Klopfenstein $(\varangle) \cdot$ V. Gendrin · P.-Y. Royer • L. Toko $\cdot$ A. Pierron · N.'driJ. Kadiane-Oussou . S. Zayet $(\square)$

Infectious Disease Department, Nord FrancheComté Hospital, 90400 Trevenans, France e-mail: timothee.klopfenstein@hnfc.frS. Zayet e-mail: souhail.zayet@gmail.com

A. Gerazime · M. Puyraveau

Methodology Unit, Clinical Investigation Center INSERM 1431, Jean-Minjoz University Hospital, Besançon, France

T. Conrozier · J.-C. Balblanc $\cdot$ A. Lohse .

C. Guillochon

Rheumatology Department, Nord Franche-Comté

Hospital, Trevenans, France

C. Mezher $\cdot$ J. Badie

Intensive Care Unit Department, Nord Franche-

Comté Hospital, Trevenans, France
19 group (pooled OR, 0.82; 95\% CI 0.73-0.93; $p=0.001$ ) but not in the non-severe COVID-19 group (pooled OR, 1.46; 95\% CI 0.91-2.34; $p=0.12$ ). For patients who were not mechanically ventilated at baseline $(5523 / 6482)$, the pooled OR $(0.74 ; 95 \%$ CI $0.64-0.85 ; p<0.0001)$ for mechanical ventilation incidence at day 28-30 was in favor of tocilizumab (cumulative incidence of $14.8 \%$ versus $19.4 \%$ in tocilizumab and control arm, respectively). This benefit was confirmed in both subgroups, i.e., severe and non-severe COVID-19.

Conclusion: Tocilizumab is an effective treatment in hospitalized patients with COVID-19 and hypoxemia by improving survival and decreasing mechanical ventilation requirement. The greatest benefit is observed in severe COVID-19.

Keywords: Coronavirus disease 2019; Metaanalysis; Randomized clinical trial; Review; Tocilizumab 


\section{Key Summary Points}

Tocilizumab reduces mortality and mechanical ventilation requirement in hospitalized patients with COVID-19 and hypoxemia.

Mortality benefit is confirmed and amplified in the severe COVID-19 group but not in the non-severe COVID-19 group.

Mechanical ventilation incidence benefit is confirmed in both groups (severe COVID-19 group and non-severe COVID19 group).

Tocilizumab is effective in COVID-19 pneumonia. The greatest benefit is observed in severe COVID-19 pneumonia.

\section{DIGITAL FEATURES}

This article is published with digital features, including a summary slide, to facilitate understanding of the article. To view digital features for this article go to https://doi.org/10.6084/ m9.figshare.14791881.

\section{INTRODUCTION}

Since December 2019, the severe acute respiratory syndrome coronavirus 2 (SARS-CoV-2) has spread around the world infecting more than 150 million people and causing more than 3 million deaths [1]. Corticosteroids have proven to reduce mortality with strong evidence [2]. Tocilizumab is the second treatment which has also been shown to reduce mortality $[3,4]$. However, randomized clinical trials (RCTs) results are heterogeneous [3-11]. Six randomized clinical trials [5-10] have not shown an impact on mortality at day 28-30 which is confirmed by meta-analysis on five of these six RCTs $[12,13]$. The lack of positive results on mortality of these RCTs contrasts with results of cohort studies [13]. The heterogenous population in RCTs seems to explain that $[14,15]$. A recent meta-analysis of these RCTs [16] has shown that the overall mortality varies widely across these RCTs (from $2 \%$ to 30\%); this considerable variation is mainly explained by patient severity at baseline. Tocilizumab seems to be effective in severe patients and subgroup analysis is needed [14-17]. For example the only subgroup analysis on severe patients in RCT was performed by Soin et al. in COVINTOC [11] and it supports this assumption: among patients who had severe coronavirus disease 2019 (COVID-19) at baseline, 16\% patients died in the tocilizumab group versus $34 \%$ in the standard care group $(p=0.04)$; in COVINTOC severe COVID-19 was defined as respiratory rate of at least $30 / \mathrm{min}$ or $\mathrm{SpO}_{2}$ less than $90 \%$ or acute respiratory distress syndrome or septic shock. The last two main RCTs (REMAP-CAP [3] and RECOVERY [4]) showed mortality benefit of tocilizumab administration.

As a result of the heterogenous population in RCTs, we think that an updated meta-analysis with subgroup analysis in severe and non-severe COVID-19 is needed; for example, such as the subgroup analysis based on severe and nonsevere COVID-19 that Soin et al. conducted in their RCT. We recently published a narrative review of these RCTs to assess an optimal group and timing for tocilizumab administration; in this review we performed a classification based on respiratory support at baseline which would be helpful for a subgroup meta-analysis [15]. However, as a result of the heterogenous description about respiratory support at baseline (different scales or clinical description were used in the RCTs) this classification cannot be used in a practical way. In these RCTs, the mortality increases in correlation with the severity of respiratory support at baseline [15]; furthermore, clinical severity at baseline is among the main risk factors associated with mortality in COVID-19 pneumonia [18-21]. So we chose to use the mortality in the control group to divide the RCTs into two groups: severe group (high mortality in the control group) and non-severe group (low mortality in the control group). The choice of the mortality rate to divide the RCTs depended on various factors: 
the inclusion period (since the beginning of the pandemic) and the study site (country) are the main factors that influence the mortality in hospitalized patients with COVID-19 [22]. Most of these RCTs included patients in the beginning of the pandemic in wealthy countries (especially North America and Europe), so we chose a mortality rate of $17 \%$ which corresponds to the in-hospital mortality in the beginning of the pandemic among COVID-19 hospitalized adults in the USA [20]. Our analysis RCTs were divided into two groups: severe COVID-19 group (mortality rate in the control group at least 17\%) and non-severe COVID-19 group (mortality rate in the control group less than $17 \%)$.

\section{METHODS}

This review was conducted in accordance with the Cochrane Handbook for Systematic Reviews (V6.1) [23] and is reported according to the PRISMA (preferred reporting items for systematic reviews and meta-analysis) statement [24]. The PICO method (population, intervention, comparison, outcome) was used before performing the literature search to formalize the objective of the study.

\section{Search Strategy and Selection Criteria}

We performed an electronic search of Medline, the Cochrane Library, and Embase on April 4, 2021, which was updated on April 27, 2021. A systematic search was done using PubMed to find MEDLINE indexed published articles and the preprint server MedR $\chi \mathrm{iv}$ to find unpublished manuscripts. As of March 27, 2021, the search was conducted by combining the MeSH words "COVID-19" AND "tocilizumab" AND "trial". In MedR $\chi$ iv the search was conducted by combining "COVID-19" AND "tocilizumab" AND "trial" AND "randomized". We then screened citations on the basis of titles and abstracts. We selected all RCTs that compared the clinical outcome of patients with COVID-19 treated with tocilizumab versus standard of care or placebo. Irrelevant manuscripts were excluded. Our primary endpoint was the 28-30 day mortality. Secondary endpoints were mechanical ventilation incidence at day 28-30 and safety endpoint (serious adverse events).

\section{Study Selection and Data Extraction}

Two independent reviewers (TK, SZ) examined each title and abstract to identify potentially eligible articles. Records deemed eligible, and records that did not contain enough information to confirm their inclusion, underwent full text review. Disagreements were resolved through discussions, and by a third reviewer (TK, SZ, or VG) if required. Another independent reviewer (MP) verified all data extraction.

\section{Risk of Bias Assessment}

We excluded studies that were not written in English or French because of the language barrier. Risk of bias was independently assessed by two reviewers (TK and SZ). Studies were judged either as "low risk", "unclear", or "high risk" according to the Cochrane Handbook for Systematic Reviews of Interventions [25]. We considered the methodological quality for each study on the basis of the following categories: selection bias, performance bias, detection bias, potential for attrition bias, potential for reporting bias, and other potential bias.

\section{Statistical Analysis}

Where suitable statistical summary data were available, we combined selected outcome data in pooled meta-analyses using the Cochrane statistical software RevMan [26]. Odds ratios (ORs) and 95\% confidence intervals (CI) were calculated to estimate the impact of tocilizumab on mortality at 28-30 days, mechanical ventilation at 28-30 days, and serious adverse events. We conducted the meta-analysis using all of the trials and then we performed a subgroup metaanalysis in the two groups generated by the severity of the patients COVID-19. We assessed statistical heterogeneity using the $I^{2}$ test to determine whether fixed effects $\left(I^{2}<50 \%\right)$ or random effects $\left(I^{2} \geq 50 \%\right)$ modelling should be used. 


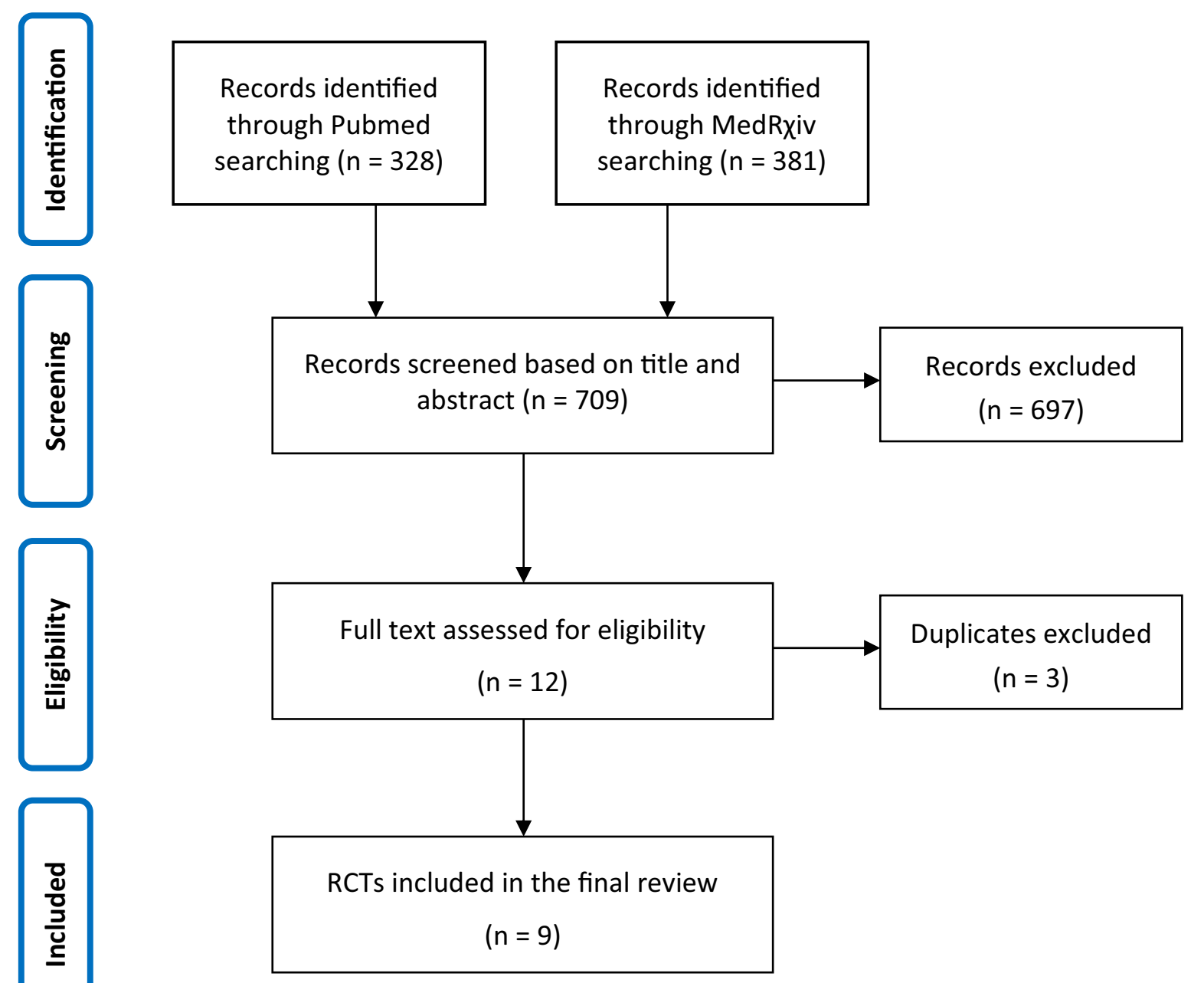

Fig. 1 PRISMA flowchart detailing the article selection process

This article is based on previously conducted studies and does not contain any new studies with human participants or animals performed by any of the authors.

\section{RESULTS}

\section{Study Selection and Characteristics}

We included nine RCTs (Fig. 1: PRISMA flowchart); the general characteristics of the nine RCTs are summarized in Table 1. One RCT was still unpublished but we got its objectives and detailed results on the preprint server MedR $\chi$ iv [4]. A total of 6482 patients were included: 3357 randomized to tocilizumab and 3125 to placebo. Concerning subgroup analysis, four RCTs had a mortality rate in the control group of at least $17 \%$ (from $18 \%$ to $36 \%$ ) and were included in the severe COVID-19 group and five RCTs had a mortality rate in the control group of less than $17 \%$ (from $2 \%$ to $12 \%$ ) and were included in the non-severe COVID-19 group (Table 2).

\section{Mortality Analysis}

Overall, the mortality rate was $24.5 \%$ (821/ $3357)$ in the tocilizumab group and $29.1 \%$ (908/ 3125 ) in the control group at day 28-30 (pooled OR, 0.85; 95\% CI 0.76-0.96; $p=0.006$; Fig. 2). 
Table 1 Characteristics of tocilizumab randomized clinical trials in COVID-19

\begin{tabular}{|c|c|c|c|c|}
\hline Studies & Study design & Country & $\begin{array}{l}\text { Number of } \\
\text { patients }\end{array}$ & TCZ regimen ${ }^{a}$ \\
\hline $\begin{array}{l}\text { Salvarini et al. [5] } \\
\quad \text { (RCT-TCZ) }\end{array}$ & $\begin{array}{l}\text { Open-label, } \\
\text { controlled trial }\end{array}$ & Italy, 24 sites & $\begin{array}{c}126 \text { patients }(60 \\
\text { in TCZ arm) }\end{array}$ & $\begin{array}{l}\text { Two doses (second dose } \\
12 \mathrm{~h} \text { later) }\end{array}$ \\
\hline $\begin{array}{l}\text { Stone et al. [6] } \\
\text { (BACC-bay) }\end{array}$ & $\begin{array}{l}\text { Double-blind, } \\
\text { placebo- } \\
\text { controlled trial }\end{array}$ & USA & $\begin{array}{l}243 \text { patients (161 } \\
\text { in TCZ arm) }\end{array}$ & Single dose \\
\hline $\begin{array}{l}\text { Salama et al. [7] } \\
\text { (EMPACTA) }\end{array}$ & $\begin{array}{l}\text { Double-blind, } \\
\text { placebo- } \\
\text { controlled trial }\end{array}$ & $\begin{array}{l}6 \text { countries in America } \\
\text { and Africa }\end{array}$ & $\begin{array}{l}389 \text { patients ( } 249 \\
\text { in TCZ arm) }\end{array}$ & $\begin{array}{l}\text { Single dose. Possibility of a } \\
\text { 2nd dose } 8-24 \text { h later }\end{array}$ \\
\hline $\begin{array}{l}\text { Hermine et al. [8] } \\
\text { (CORIMUNO- } \\
\text { TOCI) }\end{array}$ & $\begin{array}{l}\text { Open-label, } \\
\text { controlled trial }\end{array}$ & France, 9 sites & $\begin{array}{c}131 \text { patients (63 } \\
\text { in TCZ arm) }\end{array}$ & $\begin{array}{l}\text { Single dose. Possibility of a } \\
\text { 2nd dose } 48 \text { h later }\end{array}$ \\
\hline $\begin{array}{l}\text { Veiga et al. [9] } \\
\text { (TOCIBRAS) }\end{array}$ & $\begin{array}{l}\text { Open-label, } \\
\text { controlled trial }\end{array}$ & Brazil, 9 sites & $\begin{array}{l}129 \text { patients }(65 \\
\text { in TCZ arm) }\end{array}$ & Single dose \\
\hline $\begin{array}{l}\text { Soin et al. }[11] \\
\text { (COVINTOC) }\end{array}$ & $\begin{array}{l}\text { Open-label, } \\
\text { controlled trial }\end{array}$ & India, 12 sites & $\begin{array}{l}180 \text { patients (90 } \\
\text { in TCZ arm) }\end{array}$ & $\begin{array}{l}\text { Single dose. Possibility of a } \\
\text { 2nd dose } 12-168 \text { h later }\end{array}$ \\
\hline $\begin{array}{r}\text { Rosas et al. }[10] \\
\text { (COVACTA) }\end{array}$ & $\begin{array}{l}\text { Double-blind, } \\
\text { placebo- } \\
\text { controlled trial }\end{array}$ & $\begin{array}{l}9 \text { countries in Europe } \\
\text { and North America }\end{array}$ & $\begin{array}{l}444 \text { patients }(294 \\
\text { in TCZ arm) }\end{array}$ & Single dose \\
\hline $\begin{array}{l}\text { Horby et al. [4] } \\
\text { (RECOVERY) }\end{array}$ & $\begin{array}{l}\text { Open-label, } \\
\text { controlled trial }\end{array}$ & UK & $\begin{array}{l}4116 \text { patients } \\
\text { (2022 in TCZ } \\
\text { arm) }\end{array}$ & $\begin{array}{l}\text { Single dose. Possibility of a } \\
\text { 2nd dose } 12-24 \text { h later }\end{array}$ \\
\hline $\begin{array}{l}\text { Gordon et al. }[3] \\
\text { (REMAP-CAP) }\end{array}$ & $\begin{array}{l}\text { Open-label, } \\
\text { controlled trial }\end{array}$ & $\begin{array}{l}\text { Europe, Oceania, and } \\
\text { North America }\end{array}$ & $\begin{array}{l}755 \text { patients }(353 \\
\text { in TCZ arm) }\end{array}$ & $\begin{array}{l}\text { Single dose. Possibility of a } \\
\text { 2nd dose } 12-24 \text { h later }\end{array}$ \\
\hline
\end{tabular}

Considering the subgroup analysis this benefit was confirmed and amplified in the severe COVID-19 group (pooled OR, 0.82; 95\% CI $0.73-0.93 ; p=0.001$ ) but not in the non-severe COVID-19 group (pooled OR, 1.46; 95\% CI 0.91-2.34; $p=0.12$ ) (Fig. 3). The funnel plot of the meta-analysis is available in Appendix 1.

\section{Mechanical Ventilation Incidence Analysis}

For patients who were not mechanically ventilated at baseline $(5523 / 6482)$, the pooled OR $(0.74 ; \quad 95 \%$ CI $0.64-0.85 ; p<0.0001)$ for mechanical ventilation incidence at day 28-30 was in favor of tocilizumab (cumulative incidence of $14.8 \%$ versus $19.4 \%$ in tocilizumab and control arm, respectively; Fig. 4). This benefit was confirmed in both subgroups: severe 


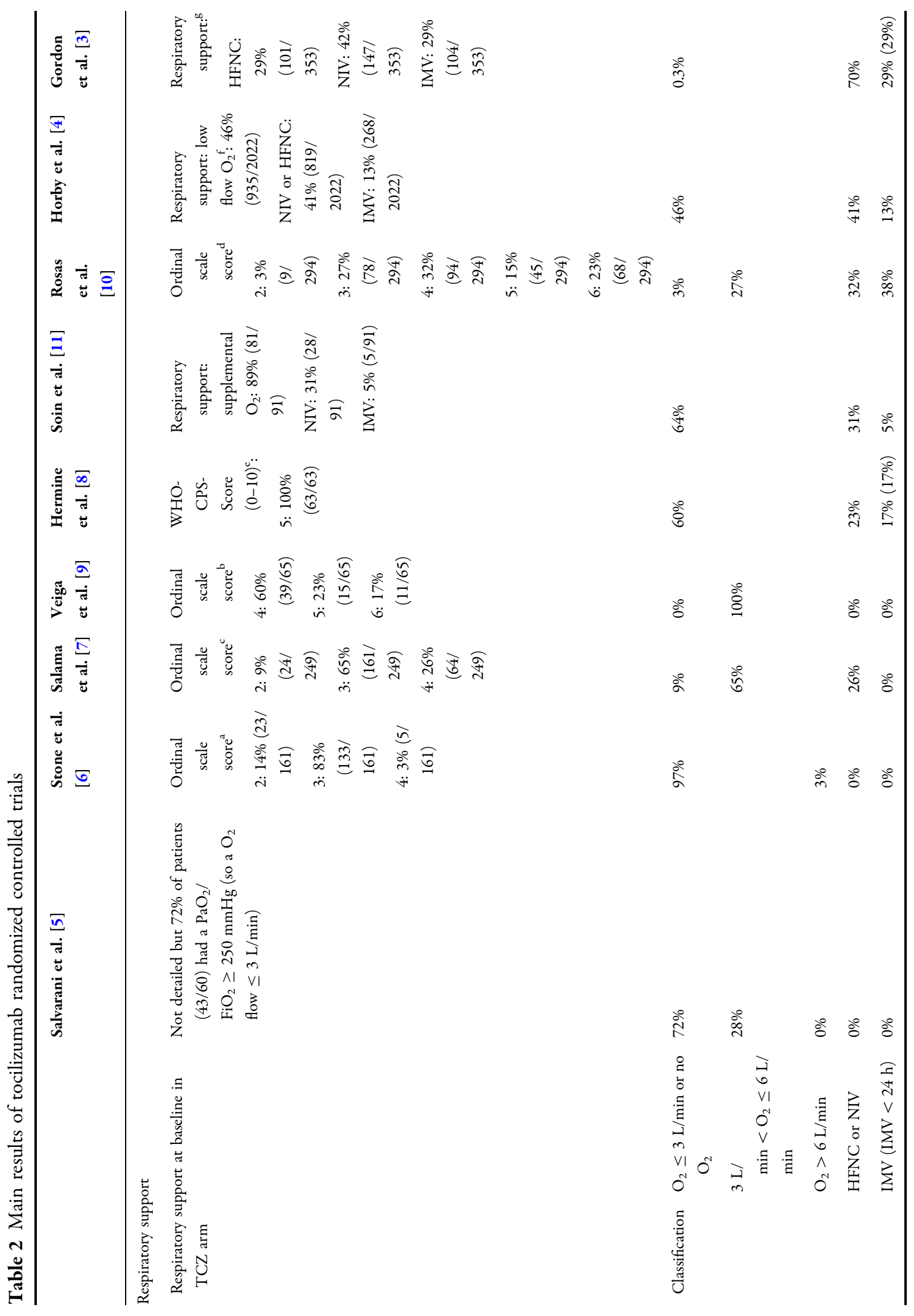




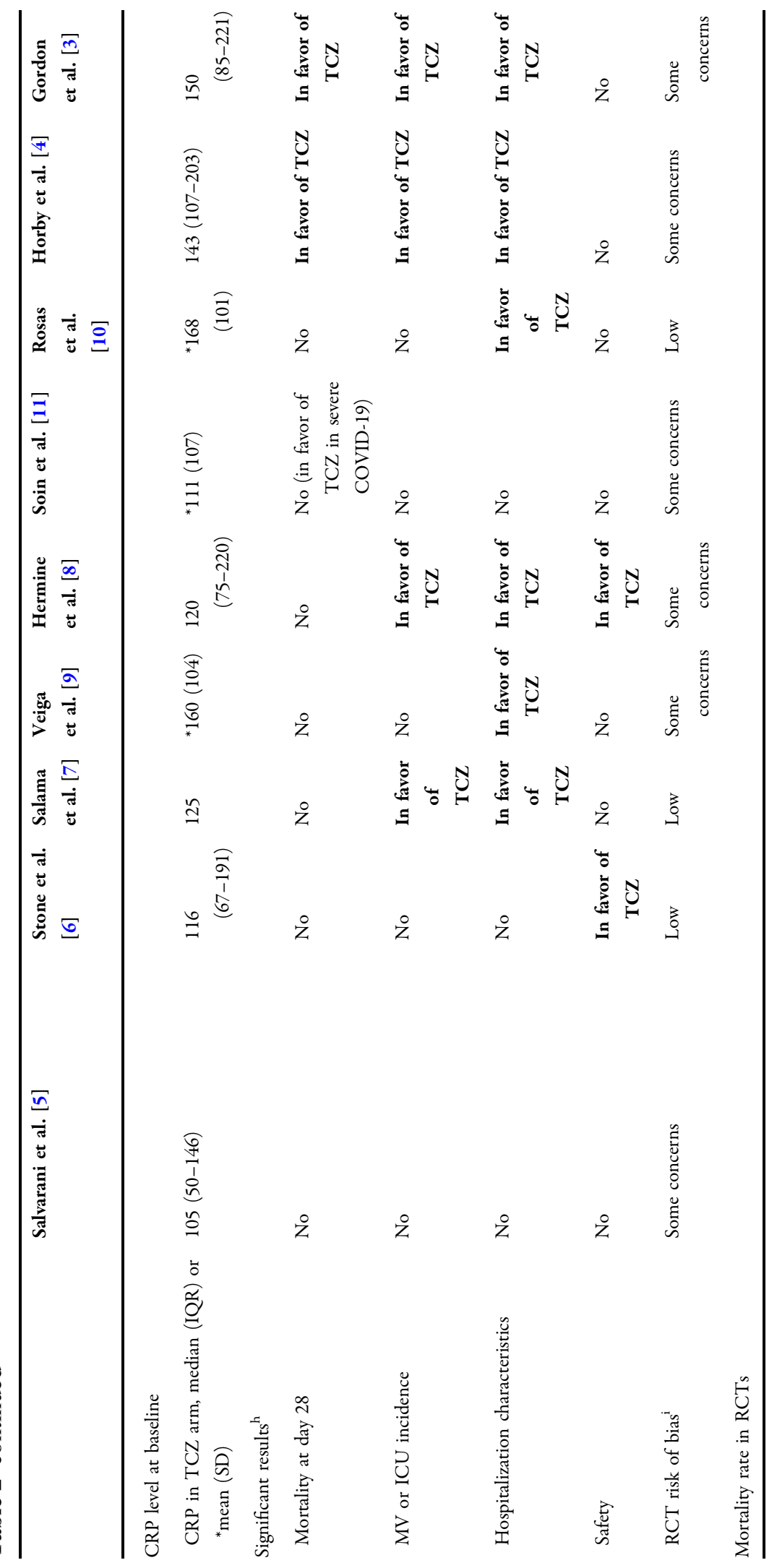




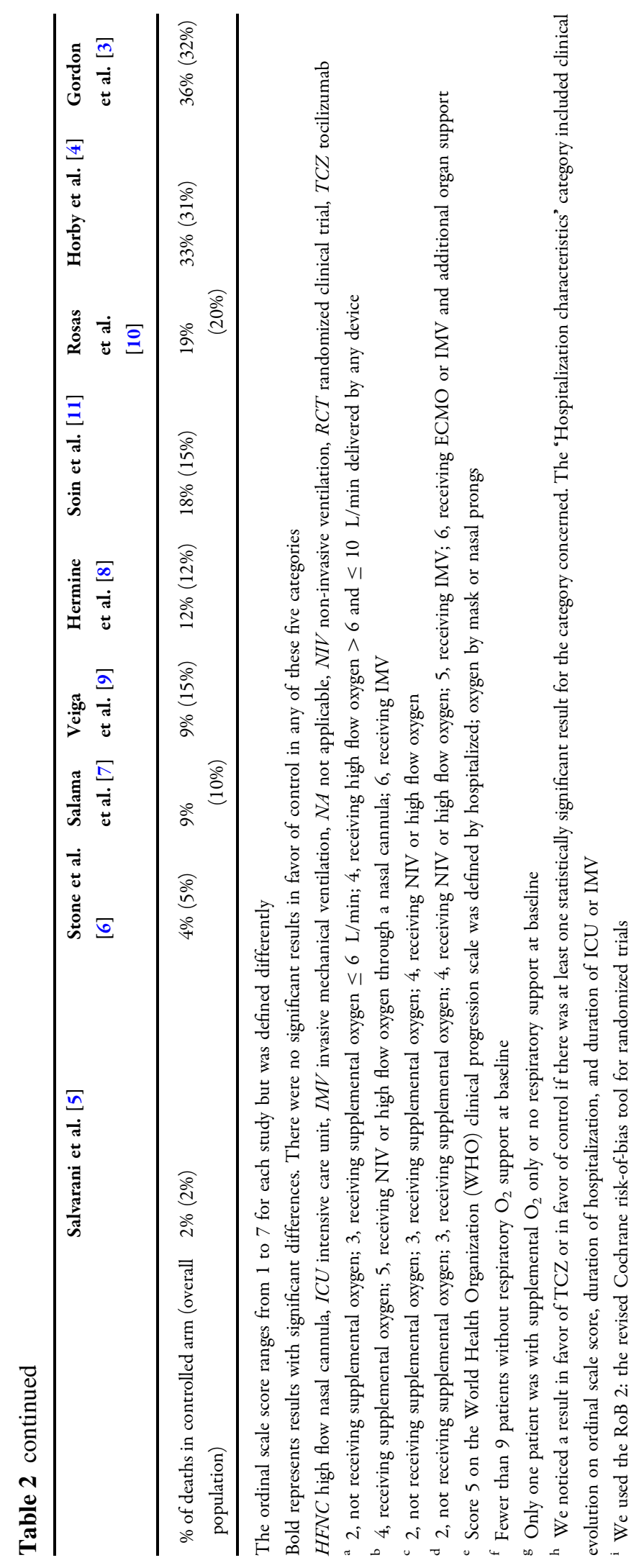




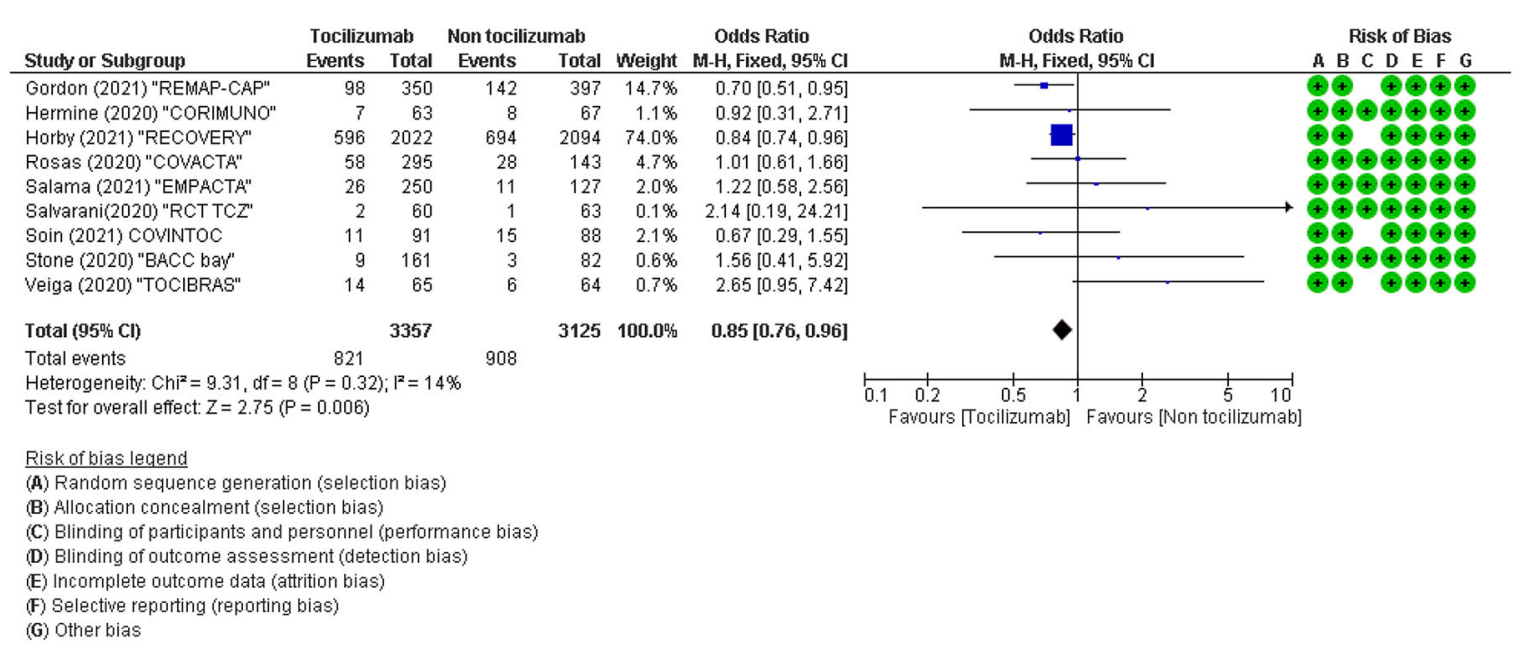

Fig. 2 Forest plot for the effect of tocilizumab on mortality at days 28-30 in randomized trials

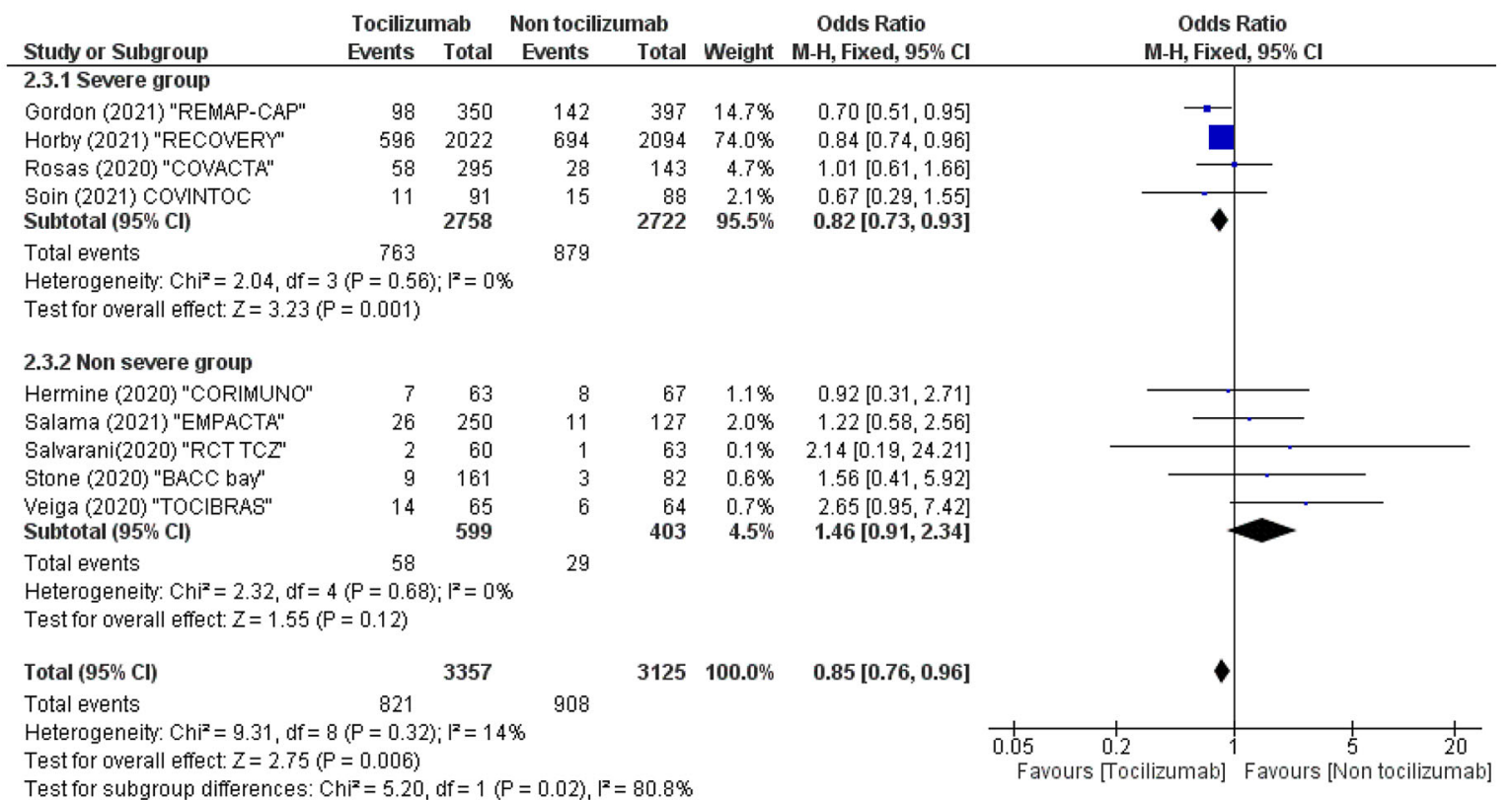

Fig. 3 Forest plot for the effect of tocilizumab on mortality at days 28-30 in randomized trials in severity event subgroup

COVID-19 group and non-severe COVID-19 group (Fig. 5).

\section{Safety Analysis}

There were no significant differences between the two arms about relative risk of serious adverse events (pooled OR, 0.87 in favor of tocilizumab; $95 \% \quad$ CI $0.69-1.11 ; \quad p=0.27$ ) (Fig. 6).

\section{DISCUSSION}

This meta-analysis shows that tocilizumab administration is an effective treatment in hospitalized patients with COVID-19 and hypoxemia by improving survival and decreasing mechanical ventilation requirement. Mortality benefit is confirmed and amplified in the severe COVID-19 group but not in the nonsevere COVID-19 group. The benefit on 


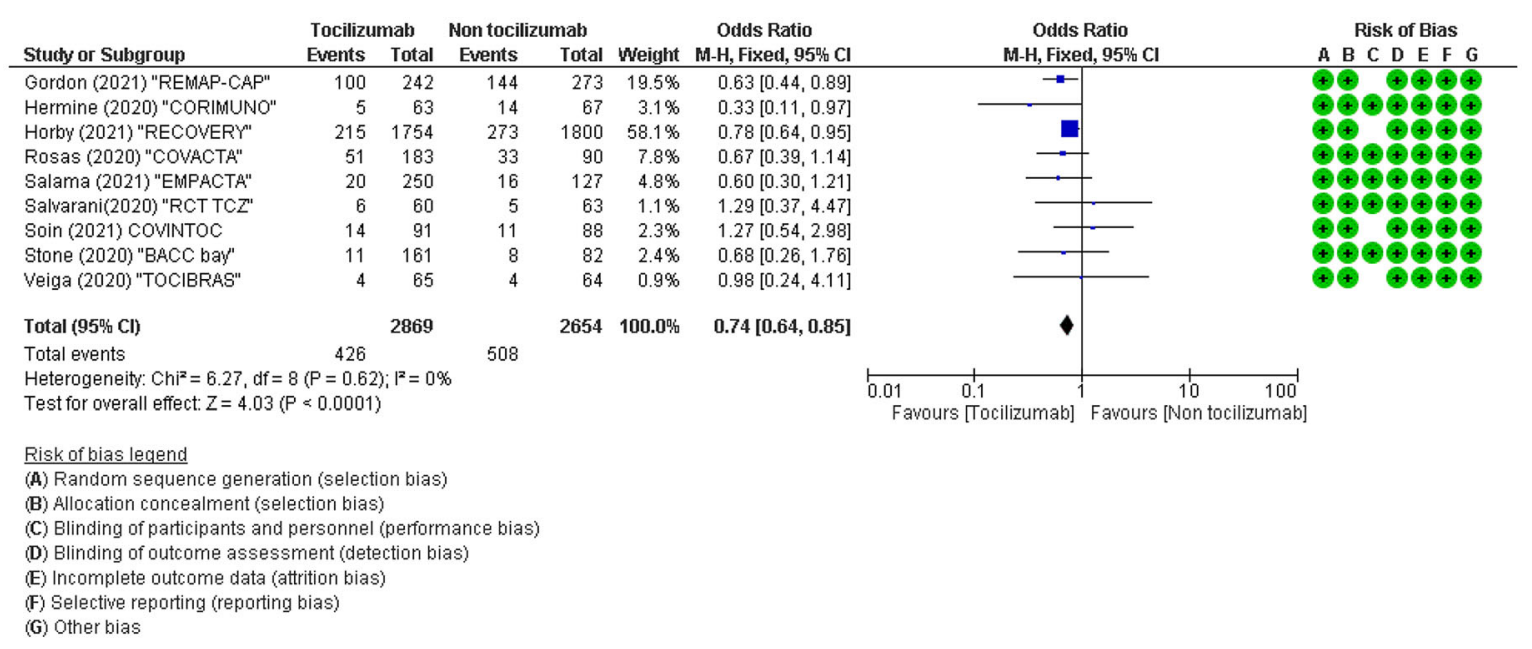

Fig. 4 Forest plot for the effect of tocilizumab on mechanical ventilation incidence at days 28-30 in randomized trials

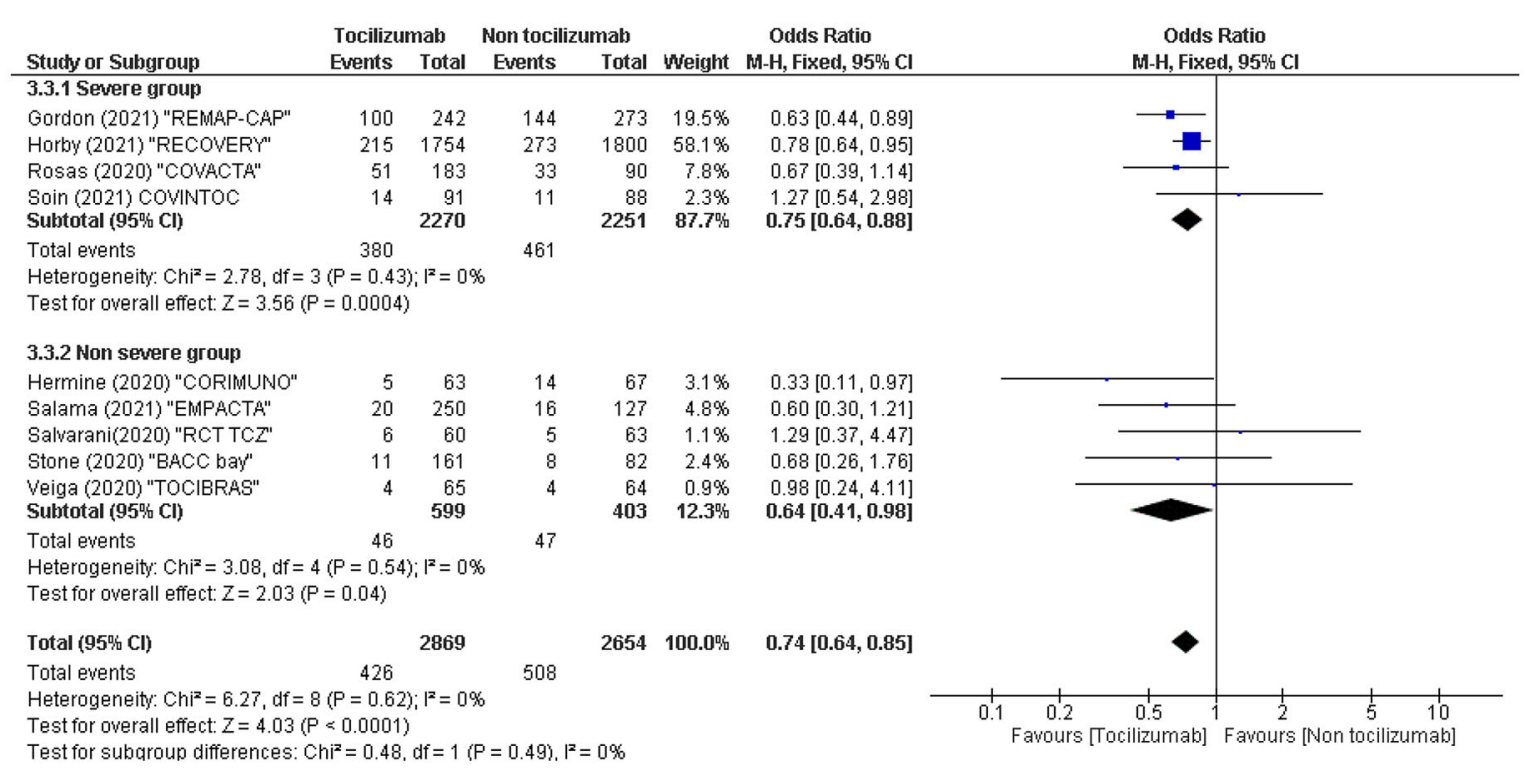

Fig. 5 Forest plot for the effect of tocilizumab on mechanical ventilation incidence at days 28-30 in randomized trials in severity event subgroup

mechanical ventilation incidence is confirmed in both subgroups: severe COVID-19 group and non-severe COVID-19 group.

\section{Meta-Analysis Results}

\section{Mortality Analysis}

Pooled OR in favor of tocilizumab shows a positive effect of tocilizumab administration on mortality at day 28-30 in hospitalized patients with COVID-19 and hypoxemia; these results are in accordance with REMAP-CAP [3] and RECOVERY [4] results. On the contrary, the seven other RCTs seemed to show no effect in favor or disfavor of tocilizumab [5-9, 11, 27]. Our main assumption to explain the lack of impact on mortality in these RCTs was they included heterogenous populations [14, 15, 17].

The subgroup analysis performed in our meta-analysis supports this assumption. 


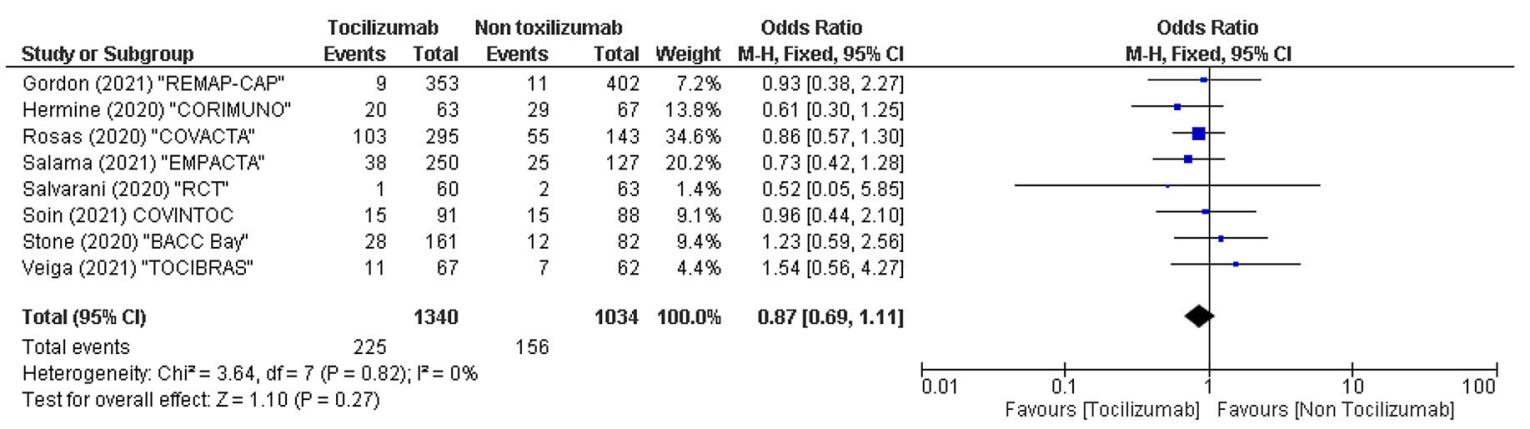

Fig. 6 Forest plot for relative risk of serious adverse events for tocilizumab versus control in randomized trials

(i) In the severe COVID-19 group, the pooled OR was clearly in favor of tocilizumab $(0.82 ; 95 \%$ CI $0.73-0.93 ; p=0.001)$ in contrast with the non-severe COVID-19 group. The test for subgroup differences suggests that there is a statistically significant subgroup effect $(p=0.02)$, meaning that severity statistically significantly modifies the effect of tocilizumab [28]. Concerning the four RCTs included in the severe COVID-19 group, results of REMAPCAP and RECOVERY were clearly in favor of tocilizumab $[2,3]$ and tocilizumab benefits were in addition to dexamethasone among patients receiving corticosteroids [4]; in COVINTOC [11] the post hoc subgroup analysis only on patients with severe COVID-19 performed by Soin et al. showed a mortality rate at $16.0 \%$ in the tocilizumab arm versus $34.1 \%$ in the control arm $(p=0.04)$. COVACTA [10] had an OR of $1.01[0.61 ; 1.66]$ without positive effect of tocilizumab administration on mortality at day 28 in the overall population; however, if we choose only patients with severe disease at an early stage (category 4 and 5 of the 7-category ordinal scale: respectively ICU (intensive care unit) or non-ICU hospital ward, requiring high-flow oxygen or noninvasive ventilation and ICU, requiring intubation and mechanical ventilationbut without extracorporeal membrane oxygenation or other organ support) the death rate is clearly lower in patients treated with tocilizumab than placebo (17\% [24/139] versus $28 \%$ [15/54]). A mortality rate of $17 \%$ is extremely low in this ICU population and contrasts with medical literature, which usually reports around 30\% [19] and reached $60 \%$ in the beginning of the pandemic [29].

(ii) Concerning the non-severe COVID-19 group, the pooled OR was 1.46 the for control arm but did not reach statistical significance $(95 \%$ CI $0.91-2.34 ; p=0.12$ ). Veiga et al.'s trial [9] was stopped early in July 2020 after an increase in deaths [30] and is the only RCT which raised the question that tocilizumab may possibly harm by increasing the risk of death. If on the one hand tocilizumab could possibly increase the risk of death in a population with a majority (60\%) of non-ICU patients [9] but on the other hand tocilizumab decreased the risk of death in the majority of ICU patients $[3,11]$ we would not see an impact on mortality in a heterogeneous population as it is in most RCTs [5-8, 10]. However, Veiga et al.'s [9] results must be viewed with caution because of the sample size of the trial and considering that there were no significant differences on mortality at day 28. Concerning the four other RCTs in the nonsevere COVID-19 group: (a) on the one hand EMPACTA [7] and CORIMUNO [8] had an OR close to 1 without benefit for tocilizumab in terms mortality; however, they both met their primary endpoint (a composite criteria including mortality and ventilation requirement), Salama et al. (EMPACTA) [7] and Hermine et al. (CORIMUNO) [8] concluded that there is a potential benefit of tocilizumab in 
COVID-19; (b) but on the other hand RCTTCZ (Salvarini et al.) [5] and BACC Bay (Stone et al.) [6] had an OR greater than 1.5 in favor of the control arm but with a wide confidence interval. These two RCTs concern a selected population of moderate-tomild COVID-19 pneumonia. In Stone et al.'s trial [6] more than $95 \%$ of patients had a level of $\mathrm{O}_{2}$ below $6 \mathrm{~L} / \mathrm{min}$ delivered by nasal cannula or no oxygen administration at baseline. In Salvarani et al.'s trial [5] we do not have the detailed description of respiratory support at baseline; however, the median $\mathrm{PaO}_{2} / \mathrm{FiO}_{2}$ was greater than $250 \mathrm{mmHg}$ (at $264.5 \mathrm{mmHg}$ ). This selected population of moderate COVID-19 pneumonia at baseline is in line with the low mortality rate in the total population in these two trial $(\leq 5 \%)$, in contrast to a proportion of $10-12 \%$ of deaths in Salama et al.'s and Hermine et al.'s trials [7, 8]. Any conclusion about RCT-TCZ and BACC Bay might not be generalized to all COVID-19 pneumonia.

\section{Mechanical Ventilation Analysis}

This meta-analysis shows that tocilizumab decreased the incidence of mechanical ventilation in hospitalized patients with COVID-19. This benefit was confirmed in both subgroups: severe COVID-19 group and non-severe COVID19 group. The nine RCTs were included in this analysis. The only one RCT with an OR greater than 1 in favor of the control arm was RCT-TCZ [5] with wide confidence intervals and benefit cannot be ruled out. As previously described in a meta-analysis including the first five RCTs [13], our meta-analysis confirms that tocilizumab decreases the incidence of mechanical ventilation in hospitalized patients with COVID-19. In countries facing a huge challenge in terms of ICU beds while dealing with this outbreak, tocilizumab may be helpful to manage the crisis epidemic context in terms of public health [31].

\section{Strengths and Limitations}

This review has strengths and limitations that should be taken into account when interpreting the results. The major limitation of the subgroup meta-analysis is that it was performed on the mortality rate in the control group and not based on patients' severity. We chose a mortality rate of $17 \%$ in the control group (to divide RCTs into severe and non-severe COVID-19) which corresponds to the in-hospital mortality in the beginning of the pandemic among hospitalized adults with COVID-19 in the USA. This number was based on data from the first COVID-19 wave in the USA and therefore may reflect imperfections in management during that early stage (e.g., lack of widespread adoption of steroids, different intubation practices) rather than being a valid cutoff point for measuring COVID-19 severity in a population, especially a population studied later in the pandemic. However most of the RCTs included patients in the beginning of the pandemic in wealthy countries (especially North America and Europe) which is why we chose this proportion and we do not think that this point compromises the differential findings of this subgroup meta-analysis. Another limitation of the subgroup meta-analysis is the proportion of patients with corticosteroids administration. Several lines of evidence suggest that tocilizumab is particularly effective when corticosteroids are used [4]. In the subgroup metaanalysis, concerning the proportion of corticosteroids administered in the tocilizumab arm, three RCTs out of five in the subgroup nonsevere COVID-19 versus one RCT out of four in the subgroup severe COVID-19 had a rate of corticosteroid administration of less than 50\%. This difference could possibly impact the result of the subgroup meta-analysis. The strengths were that we used the well-established PRISMA process and the studies were rigorously identified via a double search by two independents reviewers, with the support of experienced methodologists (MP) and a biostatistician (AG) to ensure the right search terms and highquality databases were used. We also improved the validity of the search by using PubMed for published articles and MedR $\chi$ iv for unpublished articles. Despite this detailed approach, some relevant papers may have been missed because of the search strategy, the choice of databases, inconsistent search terminology, indexing 
problems, or the filters used. However, we identified the same nine RCTs for inclusion as the most recent meta-analysis on this subject [32].

\section{Definition of Optimal Group and Timing for Tocilizumab Administration in COVID-19}

\section{We Must Learn from the Past!}

Early in the COVID-19 pandemic retrospective cohort studies suggest an association between tocilizumab and lower mortality or mechanical ventilation requirement [33-36], and these data were confirmed by a well-conducted metaanalysis of these cohorts [13]. Methodological bias alone was not enough to explain the gap between tocilizumab efficacy shown in retrospective cohort studies and the first RCTs' conclusions [13, 14, 17]. In fact, tocilizumab was mainly used as an off-label rescue treatment in critically ill patients with COVID-19 in retrospective cohorts such as in Brescia (Italy) [36] or in Nord Franche-Comté (France) [37].

\section{Primum Non Nocere!}

Tocilizumab administration in patients with COVID-19 with a low level of oxygen seems to be ineffective according to conclusions drawn by Stone et al. [6] and Salvarini et al. [5]. However, as we discussed above, the mortality rates in these two studies were below 5\% and any conclusions should be treated with caution. On the contrary, tocilizumab seems to be effective in the severe COVID-19 group and in two RCTs of the non-severe COVID-19 group (EMPACTA [7] and CORIMUNO [8]). In the discussion below, we try to assess the optimal group and timing for tocilizumab administration in COVID-19 on the basis of these six RCTs $[3,4,7,8,10,11]$.

\section{Concerning Respiratory Stage (Respiratory Support at Baseline)}

EMPACTA [7] and CORIMUNO [8] trials are the RCTs with positive results (in favor of tocilizumab) with the less severe COVID-19 (overall mortality around 10-12\%); both concerned patients before intubation stage (mechanical ventilation was a criterion of exclusion). In Hermine et al.'s trial (CORIMUNO) [8] all patients had a pneumonia with a level above $3 \mathrm{~L}$ of $\mathrm{O}_{2}$ but before ICU care (no patients on noninvasive ventilation or high flow oxygen). In Salama et al.'s trial (EMPACTA) [7], 65\% of patients received supplemental oxygen (but we do not have the details about oxygen flow) and $25 \%$ received noninvasive ventilation or high flow oxygen. At the opposite end, REMAP-CAP [3] is an RCT with positive results (in favor of tocilizumab) with the more severe COVID-19 at baseline (overall mortality around $32 \%$ ). In REMAP-CAP tocilizumab reduced mortality in patients, $29 \%$ of whom were at intubation stage and $71 \%$ were before intubation stage (29\% high flow nasal cannula and $42 \%$ with non-invasive ventilation only). Note that patients had to be enrolled within $24 \mathrm{~h}$ after starting organ support; however, we do not have the detailed outcome according to baseline category to analyze if there is any difference of response between intubated patients or patients before intubation stage at baseline; this would have been interesting. In RECOVERY [4], in the subgroup of patients with mechanical ventilation, the efficacy remains unclear: the mortality rate at day 28 was $47 \%(125 / 268)$ for tocilizumab versus $48 \%(142 / 294)$ for placebo with a median adjusted OR at 0.94 (95\% CI 0.73 to 1.19). As in RECOVERY, in COVACTA there was also no clear benefit of tocilizumab use for patients at intubation stage at baseline (category 5 and 6 of the 7-category ordinal scale with an OR at 0.89 [0.30-2.57] and 1.00 [0.50-2.02], respectively) [4].

\section{Concerning Inflammation Stage (Biological Findings at Baseline)}

Patients with evidence of inflammation have a greater benefit from tocilizumab administration than patients without or with a lower level of inflammation [38, 39]. In REMAP-CAP [38], a secondary analysis of primary outcome according to C-reactive protein (CRP) tercile subgroups shows that the optimal response was found in the highest CRP tercile (OR 1.92 [1.12-3.34] with a probability of superiority to control of 99.1\%). In RECOVERY [4] all patients had a CRP level of at least $75 \mathrm{mg} / \mathrm{L}$. In COVACTA in 
patients with high ferritin levels, tocilizumab decreased the probability of death or mechanical ventilation compared with placebo [39].

\section{Optimal Group and Timing for Tocilizumab Administration}

Treating patients with severe COVID-19 pneumonia with evidence of inflammation early seems to be the optimal population and timing for tocilizumab administration. On the basis of the discussion above, we think that tocilizumab must be discussed in addition to corticosteroids in patients with hypoxemia and biological inflammation (especially at a CRP level of $75 \mathrm{mg} / \mathrm{L}$ or above; and a level of $\mathrm{O}_{2}$ flow greater than $3 \mathrm{~L} / \mathrm{min}$ ) until early after intubation in patients on mechanical ventilation (especially during the first $24 \mathrm{~h}$ ). ICU patients with $\mathrm{O}_{2}$ flow of at least $6 \mathrm{~L} / \mathrm{min}$ or noninvasive ventilation or high flow nasal cannula seem to have the greatest benefit from tocilizumab administration. The benefits of tocilizumab remain uncertain and it could cause harm at $\mathrm{O}_{2}$ flow below $3 \mathrm{~L} / \mathrm{min}$ and later after intubation.

\section{CONCLUSION}

This meta-analysis confirmed that tocilizumab is effective in hospitalized patients with COVID19 and hypoxemia by improving survival and decreasing mechanical ventilation requirement. The greatest benefit is observed in patients with severe COVID-19.

\section{ACKNOWLEDGEMENTS}

The authors thank Mrs Charlotte Bourgoin and Elodie Bouvier for their strong implication in the present work. They also thank the management team of the Hospital Nord FrancheComte and the pharmacists team for having made available tocilizumab outside its approved indication. Special acknowledgements to the whole HNFC tocilizumab multidisciplinary team and to all the physicians, caregivers (nurses and orderlies), and patients.
Funding. This research did not receive any specific grant from funding agencies in the public, commercial, or not-for-profit sectors. The Journal's Rapid Service Fee was funded by the authors.

Authorship. All named authors meet the International Committee of Medical Journal Editors (ICMJE) criteria for authorship for this article, take responsibility for the integrity of the work as a whole, and have given their approval for this version to be published.

Authorship Contributions. Timothée Klopfenstein, Souheil Zayet, and Vincent Gendrin drafted the manuscript. Aurélie Gerazime and Marc Puyraveau performed the statistical analysis. All authors revised the final manuscript.

Disclosures. All authors confirm that they have nothing to disclose.

Compliance with Ethics Guidelines. This article is based on previously conducted studies and does not contain any new studies with human participants or animals performed by any of the authors.

Data Availability. The data presented are available on request from the corresponding author.

Open Access. This article is licensed under a Creative Commons Attribution-NonCommercial 4.0 International License, which permits any non-commercial use, sharing, adaptation, distribution and reproduction in any medium or format, as long as you give appropriate credit to the original author(s) and the source, provide a link to the Creative Commons licence, and indicate if changes were made. The images or other third party material in this article are included in the article's Creative Commons licence, unless indicated otherwise in a credit line to the material. If material is not included in the article's Creative Commons licence and your intended use is not permitted by statutory regulation or exceeds the permitted use, you will need to obtain permission directly from the 
copyright holder. To view a copy of this licence, APPENDIX visit http://creativecommons.org/licenses/by$\mathrm{nc} / 4.0 /$.

Figures7, 8, 9, 10, and 11.

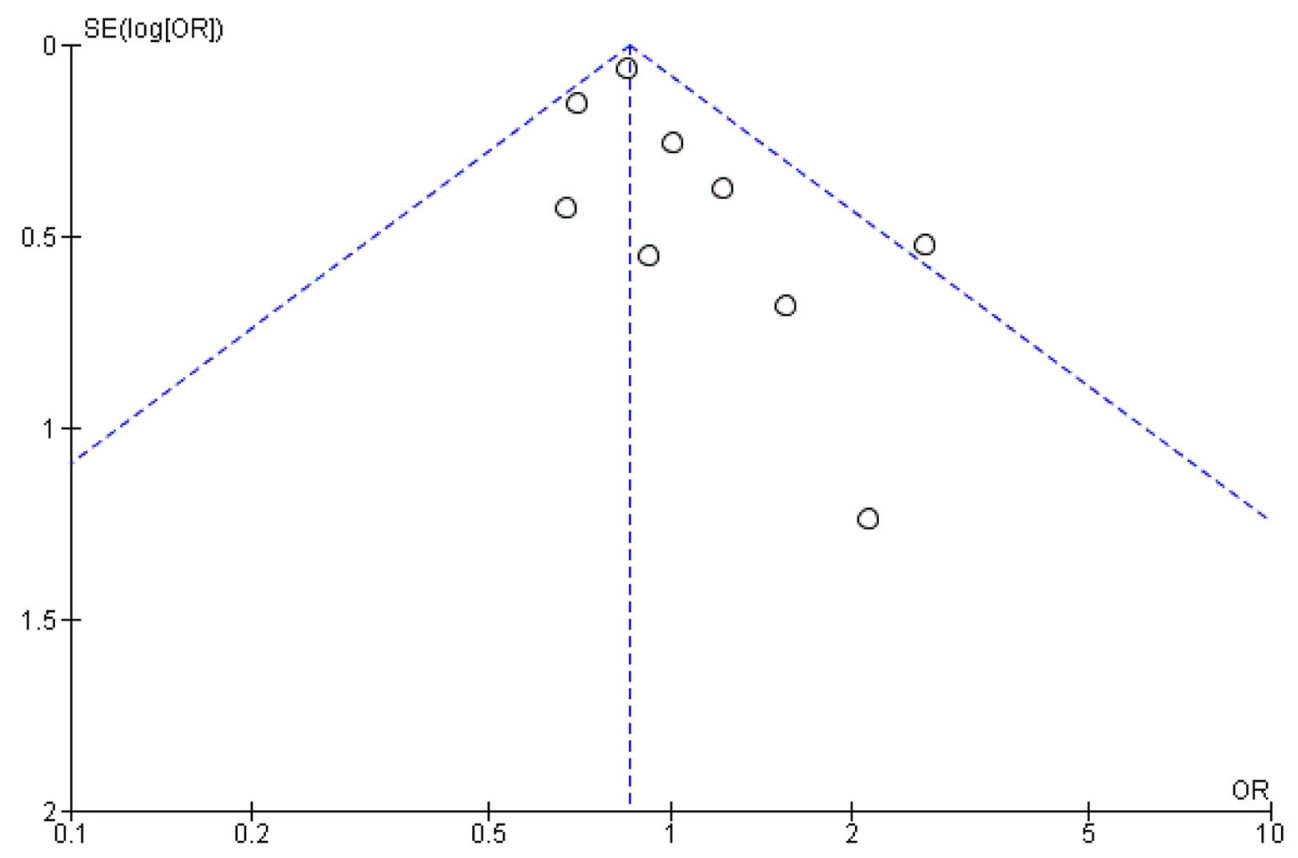

Fig. 7 Funnel plot for the effect of tocilizumab on mortality at days $28-30$ in randomized trials

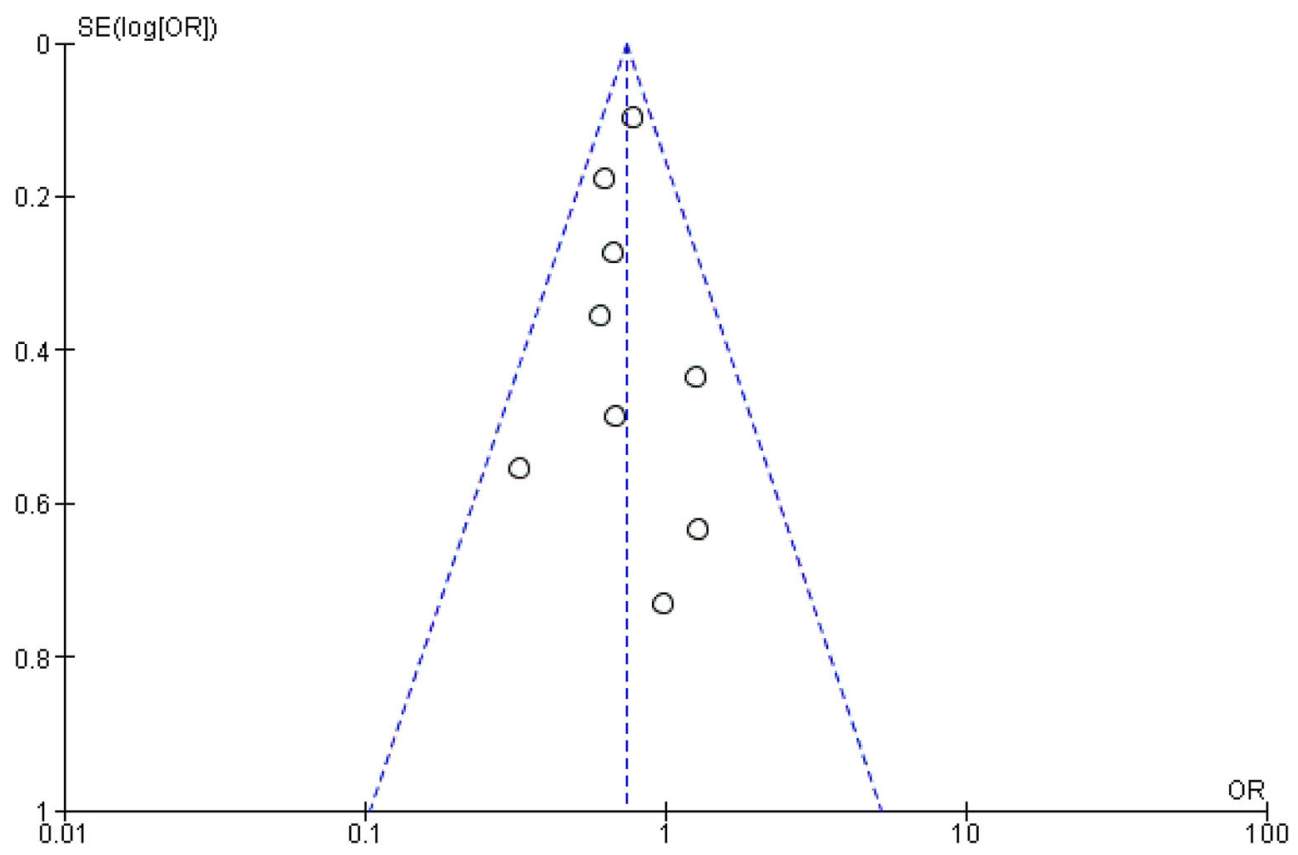

Fig. 8 Funnel plot for the effect of tocilizumab on mechanical ventilation incidence at days 28-30 in randomized trials 


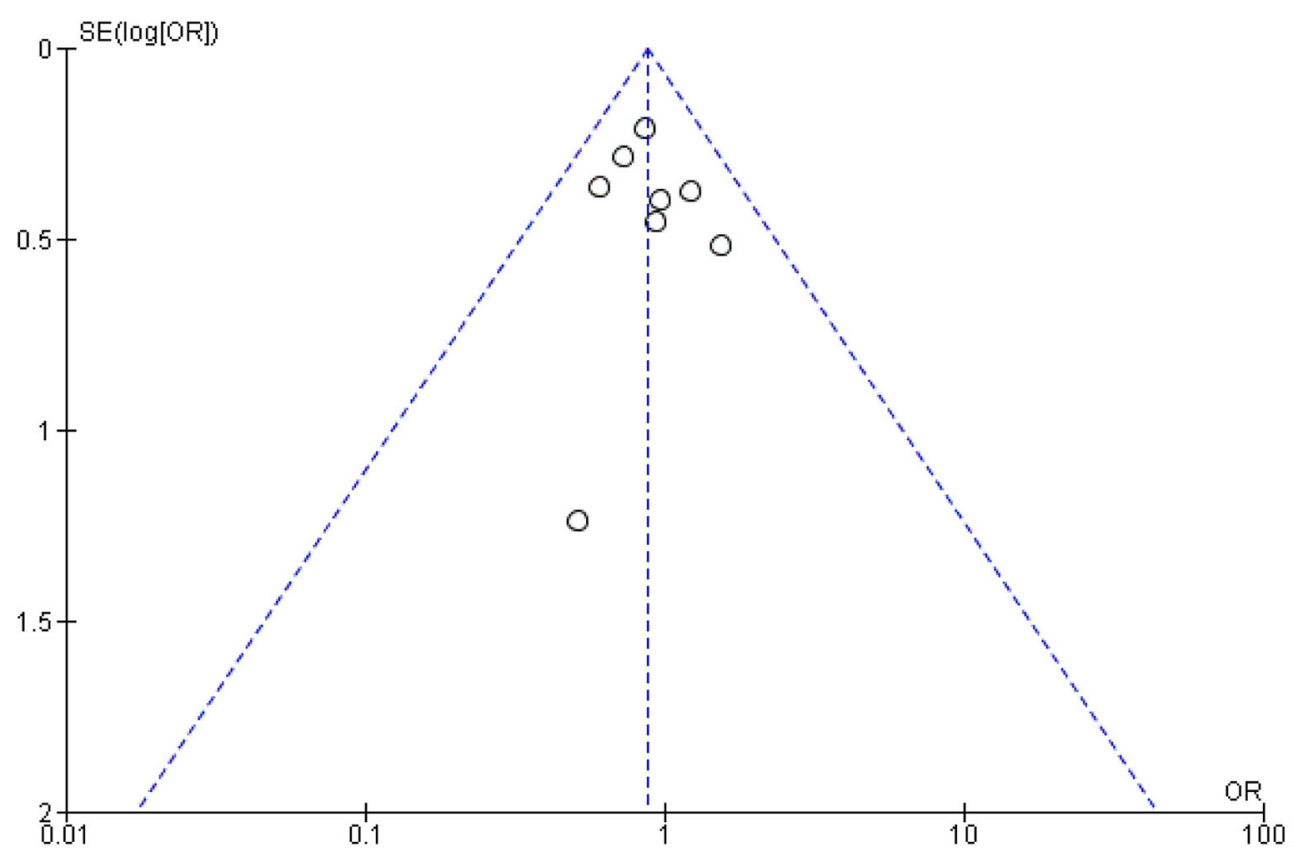

Fig. 9 Funnel plot for relative risk of serious adverse events for tocilizumab versus control in randomized trials

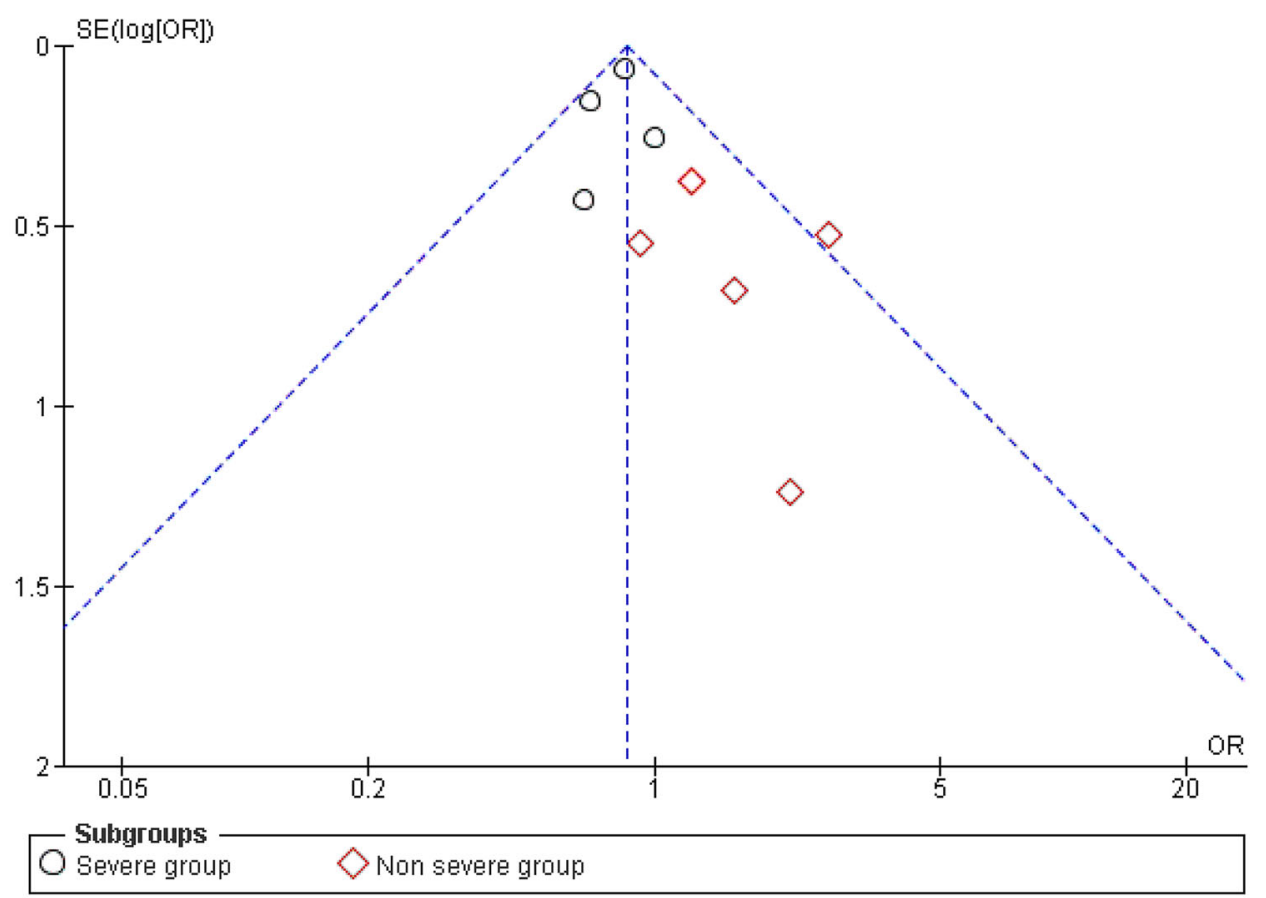

Fig. 10 Funnel plot for the effect of tocilizumab on mortality at days 28-30 in randomized trials in severity event subgroup 


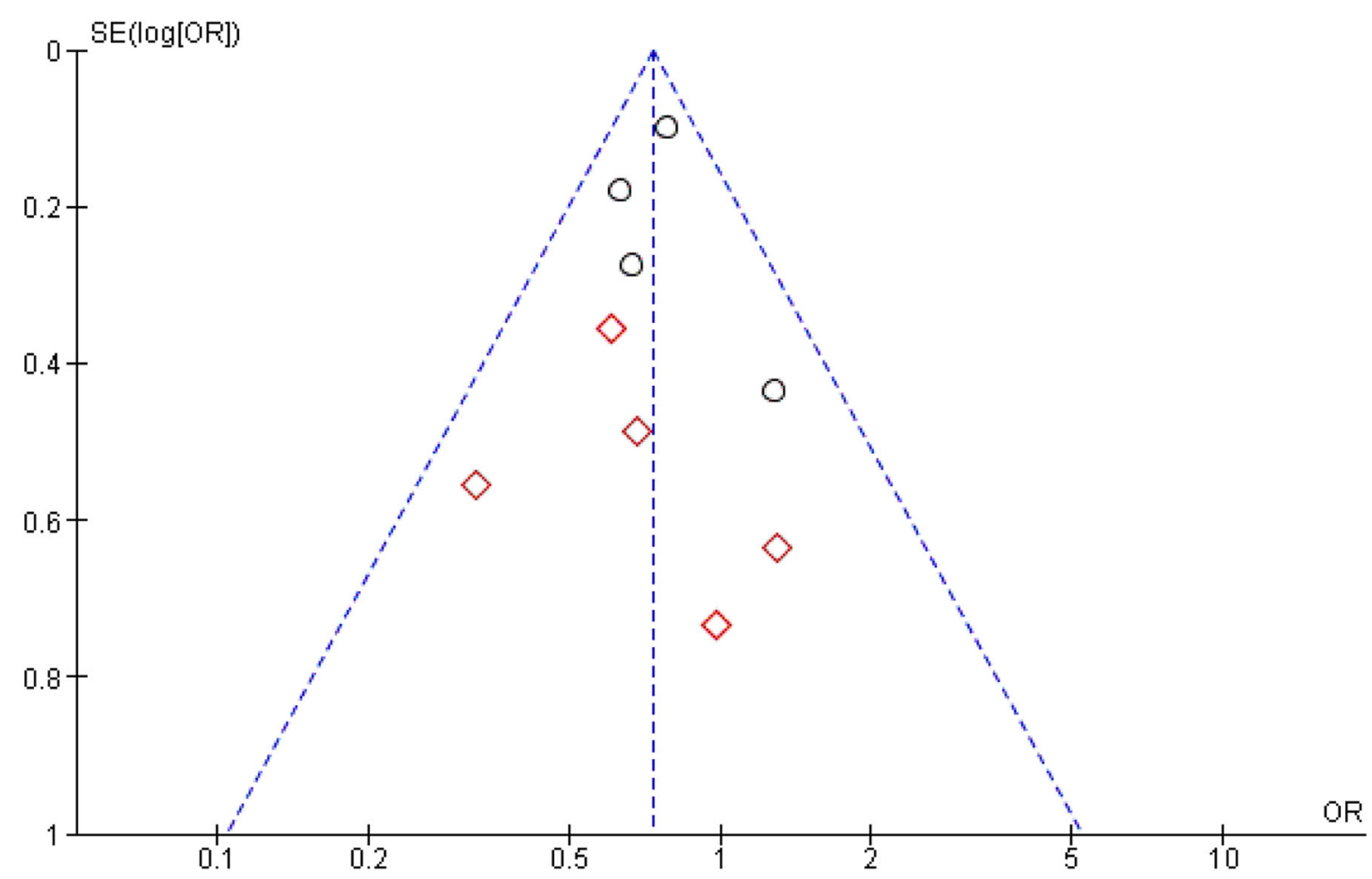

Subgroups

Severe group

Non severe group

Fig. 11 Funnel plot for the effect of tocilizumab on mechanical ventilation incidence at days 28-30 in randomized trials in severity event subgroup

\section{REFERENCES}

1. WHO Coronavirus Disease (COVID-19) Dashboard. https://covid19.who.int. Accessed 5 May 2021.

2. RECOVERY Collaborative Group, Horby P, Lim WS, et al. Dexamethasone in hospitalized patients with Covid-19-preliminary report. N Engl J Med. 2020.

3. REMAP-CAP Investigators, Gordon AC, Mouncey $\mathrm{PR}$, et al. Interleukin-6 receptor antagonists in critically ill patients with Covid-19. N Engl J Med. 2021;384:1491-1502.

4. RECOVERY Collaborative Group, Horby PW, Pessoa-Amorim G, et al. Tocilizumab in patients admitted to hospital with COVID-19 (RECOVERY): preliminary results of a randomised, controlled, open-label, platform trial. medRxiv. https://doi.org/ 10.1101/2021.02.11.21249258v1. Accessed 11 Mar 2021.

5. Salvarani C, Dolci G, Massari M, et al. Effect of tocilizumab vs standard care on clinical worsening in patients hospitalized with COVID-19 pneumonia: a randomized clinical trial. JAMA Intern Med. 2021;181(1):24-31.

6. Stone JH, Frigault MJ, Serling-Boyd NJ, et al. Efficacy of tocilizumab in patients hospitalized with Covid-19. N Engl J Med. 2020;383(24):2333-44.

7. Salama C, Han J, Yau L, et al. Tocilizumab in patients hospitalized with Covid-19 pneumonia. N Engl J Med. 2021;384(1):20-30.

8. Hermine O, Mariette X, Tharaux P-L, et al. Effect of tocilizumab vs usual care in adults hospitalized with COVID-19 and moderate or severe pneumonia: a randomized clinical trial. JAMA Intern Med. 2021;181(1):32-40.

9. Veiga VC, Prats JAGG, Farias DLC, et al. Effect of tocilizumab on clinical outcomes at 15 days in patients with severe or critical coronavirus disease 2019: randomised controlled trial. BMJ. 2021;372: n84. 
10. Rosas IO, Bräu N, Waters M, et al. Tocilizumab in hospitalized patients with severe Covid-19 pneumonia. N Engl J Med. 2021;384(16):1503-16.

11. Soin AS, Kumar K, Choudhary NS, et al. Tocilizumab plus standard care versus standard care in patients in India with moderate to severe COVID19-associated cytokine release syndrome (COVINTOC): an open-label, multicentre, randomised, controlled, phase 3 trial. Lancet Respir Med. 2021. https://doi.org/10.1016/S2213-2600(21)00081-3.

12. Huang Y-T, Chao C-M, Lai C-C. The impact of tocilizumab on the mortality of patients with COVID-19. Clin Infect Dis. 2020. https://doi.org/ 10.1093/cid/ciaa1738.

13. Tleyjeh IM, Kashour Z, Damlaj M, et al. Efficacy and safety of tocilizumab in COVID-19 patients: a living systematic review and meta-analysis. Clin Microbiol Infect. 2021;27(2):215-27.

14. Klopfenstein T, Conrozier T, Kadiane-Oussou NJ, Gendrin V, Zayet S, HNF Hospital Tocilizumab multidisciplinary team. Is there still a place for tocilizumab in COVID-19? Open Forum Infect Dis. 20218(2):ofab013.https://doi.org/10.1093/ofid/ ofab013. Accessed 29 Jan 2021.

15. Klopfenstein T, Gendrin V, Kadiane-Oussou NJ, Conrozier T, Zayet S, HNF Hospital Tocilizumab Multidisciplinary Team. Tocilizumab in COVID-19 pneumonia: practical proposals based on a narrative review of randomised trials. Rev Med Virol. 2021;e2239. https://doi.org/10.1002/rmv.2239.

16. Tharmarajah E, Buazon A, Patel V, et al. IL-6 inhibition in the treatment of COVID-19: a meta-analysis and meta-regression. J Infect. 2021;82(5): 178-85.

17. Richier Q, Plaçais L, Lacombe K, Hermine O. Tocilizumab in COVID-19: give it time! Clin Infect Dis. 2021. https://doi.org/10.1093/cid/ciab081.

18. Weiss P, Murdoch DR. Clinical course and mortality risk of severe COVID-19. Lancet. 2020;395(10229): 1014-5.

19. Zhou F, Yu T, Du R, et al. Clinical course and risk factors for mortality of adult inpatients with COVID-19 in Wuhan, China: a retrospective cohort study. Lancet. 2020;395(10229):1054-62.

20. Kim L, Garg S, O'Halloran A, et al. Risk factors for intensive care unit admission and in-hospital mortality among hospitalized adults identified through the US Coronavirus Disease 2019 (COVID-19)-Associated Hospitalization Surveillance Network (COVID-NET). Clin Infect Dis. 2021;72(9): e206-e214. https://doi.org/10.1093/cid/ciaa1012. Accessed 9 Feb 2021.
21. Grasselli G, Greco M, Zanella A, et al. Risk factors associated with mortality among patients with COVID-19 in Intensive Care Units in Lombardy, Italy. JAMA Intern Med. 2020;180(10):1345-55.

22. Boudourakis L, Uppal A. Decreased COVID-19 mortality-a cause for optimism. JAMA Intern Med. 2021;181(4):478-9.

23. Higgins J, Thomas J, Chandler J, et al. Cochrane handbook for systematic reviews of interventions version 6.2. 2021. https://training.cochrane.org/ handbook/current. Accessed 27 Apr 2021.

24. Moher D, Shamseer L, Clarke M, et al. Preferred reporting items for systematic review and metaanalysis protocols (PRISMA-P) 2015 statement. Syst Rev. 2015;4:1.

25. Higgins JPT, Altman DG, Gøtzsche PC, et al. The Cochrane Collaboration's tool for assessing risk of bias in randomised trials. BMJ. 2011;343:d5928.

26. The Cochrane collaboration. Review Manager. 2020. https://revman.cochrane.org. Accessed 27 Apr 2021.

27. Rosas I, Bräu N, Waters $\mathrm{M}$, et al. Tocilizumab in hospitalized patients with COVID-19 pneumonia. medRxiv. 2020. https://doi.org/10.1101/2020.08. 27.20183442 .

28. Richardson M, Garner P, Donegan S. Interpretation of subgroup analyses in systematic reviews: a tutorial. Clin Epidemiol Glob Health. 2019;7(2):192-8.

29. Yang X, Yu Y, Xu J, et al. Clinical course and outcomes of critically ill patients with SARS-CoV-2 pneumonia in Wuhan, China: a single-centered, retrospective, observational study. Lancet Respir Med. 2020;8(5):475-81.

30. Mahase E. Covid-19: arthritis drug trial for severe illness is stopped early after increase in deaths. BMJ. 2021;372:n186.

31. NHS patients to receive life-saving COVID-19 treatments that could cut hospital time by 10 days. GOV.UK. https://www.gov.uk/government/news/ nhs-patients-to-receive-life-saving-covid-19treatments-that-could-cut-hospital-time-by-10days. Accessed 9 Feb 2021.

32. RECOVERY Collaborative Group. Tocilizumab in patients admitted to hospital with COVID-19 (RECOVERY): a randomised, controlled, open-label, platform trial. Lancet. https://www.thelancet.com/ journals/lancet/article/PIIS0140-6736(21)00676-0/ fulltext. Accessed 3 May 2021. 
33. Luo P, Liu Y, Qiu L, Liu X, Liu D, Li J. Tocilizumab treatment in COVID-19: a single center experience. J Med Virol. 2020;92(7):814-8.

34. Klopfenstein T, Zayet S, Lohse A, et al. Tocilizumab therapy reduced intensive care unit admissions and/or mortality in COVID-19 patients. Med Mal Infect. 2020;50(5):397-400.

35. Roumier M, Paule R, Vallée A, et al. Tocilizumab for severe worsening COVID-19 pneumonia: a propensity score analysis. J Clin Immunol. 2021;41(2):303-14.

36. Toniati P, Piva S, Cattalini M, et al. Tocilizumab for the treatment of severe COVID-19 pneumonia with hyperinflammatory syndrome and acute respiratory failure: a single center study of 100 patients in Brescia, Italy. Autoimmun Rev. 2020;19(7):102568.
37. Klopfenstein $\mathrm{T}$, Zayet $\mathrm{S}$, Lohse A, et al. Impact of tocilizumab on mortality and/or invasive mechanical ventilation requirement in a cohort of 206 COVID-19 patients. Int J Infect Dis. 2020;99:491-5.

38. Gordon AC, Al-Beidh F, Rowan KM, et al. Interleukin-6 receptor antagonists in critically ill patients with Covid-19-preliminary report. medRxiv. 2021. https://doi.org/10.1101/2021.01. 07.21249390 .

39. Tom J, Bao M, Tsai L, Qamra A, et al. Prognostic and predictive biomarkers in patients with COVID-19 treated with tocilizumab in a randomised controlled trial. medRxiv. 2020. https://doi.org/10. $1101 / 2020.12 .23 .20247379$. 